\title{
GERENCIAMENTO DE RESÍDUOS SÓLIDOS URBANOS EM TARUMÃ E TEODORO SAMPAIO - SP
}

\section{Management Urban Solid Wastes in Tarumã and Teodoro Sampaio Cities, Brazil}

Diana da Cruz Fagundes

Mestre em Geografia pela Faculdade de Ciências e Tecnologia/UNESP/Presidente Prudente/SP

São José dos Campos/SP - Brasil dianafag@yahoo.com.br

Artigo recebido para publicação em 23/11/08 e aceito para publicação em 30/07/09

RESUMO: Nesta pesquisa estabeleceu-se como objetivo geral analisar a gestão dos resíduos sólidos domiciliares gerados nas cidades de Tarumã e Teodoro Sampaio-SP, com a finalidade de propor açães para o gerenciamento integrado dos resíduos sólidos urbanos. Foram investigados a geração, o tratamento e a destinação dos resíduos sólidos domiciliares, além daqueles gerados no processo de produção da Usina de Açúcar e Álcool Nova América, e sua participação na vida econômica da Usina de Triagem e Compostagem de Tarumã. Esta pesquisa permitiu compreender a importância de uma gestão integrada dos resíduos sólidos visando a combater e minimizar impactos ambientais associados aos mesmos, bem como enfatizar a necessidade de articular a usina de triagem de resíduos sólidos domiciliares com a coleta seletiva em Tarumã e viabilizar a coleta seletiva em Teodoro Sampaio, garantindo assim, ganhos sociais, operacionais, econômicos, educacionais e ambientais para os municípios.

Palavras-chave: Gerenciamento integrado. Resíduos sólidos domiciliares. Catadores.

ABSTRACT: This research established itself as an objective look at the general management of domestic solid wastes generated in Tarumã and Teodoro Sampaio cities, with the finality of proposing actions to the integrated management of the municipal solid wastes. We investigated the generation, treatment and allocation of domestic solid wastes, besides those generated in the production process of Sugar and Alcohol Usina Nova America, and its participation in the economic life of the Power Plant of screening and composting of Tarumã. This research permited us to understand the importance of an integrated solid wastes management aiming to combat and minimize environmental impacts associated themselves even so, emphasize the necessity to articulate the sorting plant of domestic solid wastes collection with the selective in Tarumã and turn able the selective collection in Teodoro Sampaio, granting so, social gains, operational, economic, and environmental education gains the cities.

Keywords: Integrated Management. Urban solid waste. Garbage pickers. 


\section{INTRODUÇÃO}

Tratar e dispor os resíduos provenientes das atividades urbanas sempre foi uma grande preocupação das administrações municipais e demais atores envolvidos na área de saneamento ambiental.

No entanto, na maioria dos municípios brasileiros de pequeno porte a administração se limita a varrer os logradouros e recolher o lixo domiciliar depositando-os em locais distantes da visão dos moradores, sem que haja uma real preocupação com os cuidados sanitários para a disposição adequada desses resíduos.

Dentre os problemas sérios causados pela inadequada disposição dos resíduos, dadas as suas características físicas, químicas e biológicas estão, a conta- minação do solo e da água (superficial e subterrânea), geração de odores, ou ainda, atração e proliferação de patógenos e vetores, caso não seja coletado, tratado e disposto de maneira adequada. Esse quadro se agrava com a constatação de uma tendência de crescimento da geração de resíduos. Tais fatores legitimam a necessidade de buscar alternativas eficazes para o seu equacionamento.

No Brasil, segundo IPT/CEMPRE (2000) e IBGE (2002), diariamente são geradas 241.614 toneladas de resíduos que, geralmente, são descartados como lixo.

Como pode ser observado no GRÁF. 1, 76\% do total de lixo gerado no Brasil é disposto a céu aberto, e apenas $24 \%$ são destinados a aterros, usinas de triagem e compostagem ou incineração.

GRÁFICO 1. Destinação dos Resíduos Sólidos Domiciliares no Brasil

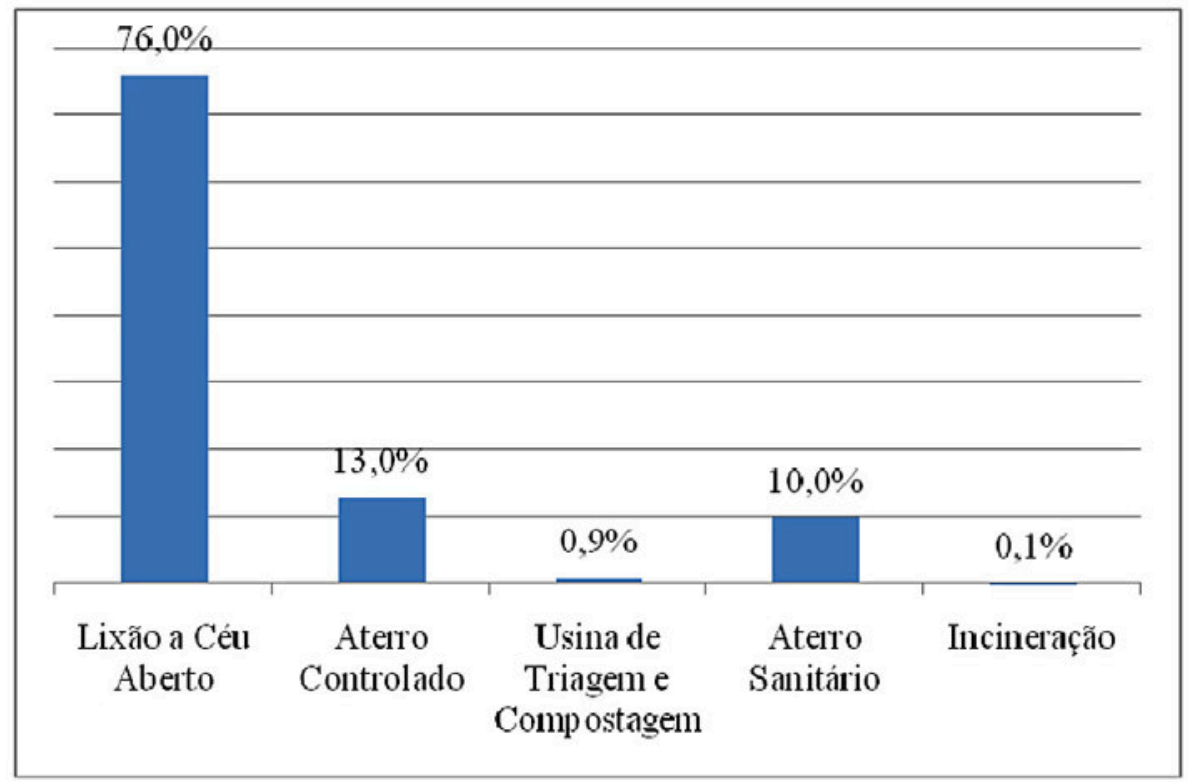

Fonte: IPT / CEMPRE - 2002. Adaptado.

Além dos grandes centros, cidades de pequeno porte, como Teodoro Sampaio e Tarumã, também sofrem com problemas decorrentes dos resíduos sólidos. Dentre esses problemas, destacam-se os relativos à sua geração, tratamento e disposição.
Outro grande desafio para o problema dos resíduos sólidos existentes no Brasil está no campo do gerenciamento. Há necessidade de priorizar a definição de políticas para esse setor que envolva todos os níveis de governo, seja ele municipal, estadual, ou federal. 
Nesse sentido, considerando as questões tecnológicas, econômicas, sociais e ambientais que envolvem as ações necessárias num adequado gerenciamento dos resíduos, torna-se necessário envolver também os mais variados setores públicos, privados e seguimentos organizados da sociedade civil (SAVI, 2005, p. 21).

Não menos importante, no gerenciamento dos resíduos deve-se considerar os catadores, que nas ruas beneficiam a limpeza urbana e passam despercebidos. Assim, eles coletam resíduos sólidos recicláveis antes do caminhão da coleta comum da prefeitura reduzindo os gastos com a limpeza pública e os comercializam com intermediários que os encaminham para a indústria, gerando empregos e poupando recursos naturais. (JARDIM, 1996, p. 138).

No entanto, apesar dos trabalhadores catadores de resíduos recicláveis, como conseqüência de suas atividades diárias, contribuírem indiretamente para o gerenciamento municipal dos resíduos sólidos, uma vez que reduzem a quantidade de resíduos a serem coletados pelas empresas de limpeza pública e promovem o aumento da vida útil dos aterros, geralmente não recebem qualquer tipo de apoio das administrações públicas ou das empresas para a realização de seu trabalho.

É preciso, portanto, inserir esses catadores num programa de coleta seletiva que considere a importância de sua contribuição no gerenciamento integrado dos resíduos sólidos urbanos.

Dados relativos à geração e destinação dos resíduos foram acompanhados através dos Inventários Estaduais de Resíduos Sólidos publicados pela CETESB, que para apresentação dos seus dados considera as Bacias Hidrográficas como Unidades de Gerenciamento.

Cidades consideradas de pequeno porte poucas vezes são priorizadas nas discussões acadêmicas e órgãos reguladores sobre a importância da adequada destinação dos seus resíduos. Tal questão despertou ainda mais nosso interesse por este estudo.
Nesse contexto, a realização desta pesquisa buscou contribuir para a tomada de decisões por parte das administrações públicas das cidades de Tarumã e Teodoro Sampaio, relacionadas com estratégias de gerenciamento integrado de resíduos sólidos, que visem à prevenção da poluição, diminuição da geração e disposição de resíduos sólidos em aterros e organização dos trabalhadores catadores de materiais recicláveis em cidades de pequeno porte.

\section{O GERENCIAMENTO DE RESÍDUOS SÓLIDOS EMTARUMÃ E TEODORO SAMPAIO}

\subsection{Tarumã}

O município de Tarumã, com população estimada de 12.571 habitantes, conforme IBGE (2006) apresenta uma população urbana composta por aproximadamente 11.474 pessoas. Nesta cidade, os serviços de varrição são realizados por empresa terceirizada e os demais serviços, ou seja, coleta, transporte e disposição dos resíduos sólidos são realizados pela Prefeitura Municipal.

Os resíduos coletados são de tipo domiciliar, de construção civil, comercial, público, de varrição e de serviços de saúde, resultando num total de 5,1 toneladas diária, sendo 4,2 ton/dia destes provenientes da produção de resíduos sólidos domiciliares, segundo dados do Inventário Estadual de Resíduos Sólidos (2006). No entanto, não é realizada pesagem periódica dos caminhões de coleta, o que dificulta uma maior precisão sobre a quantidade de resíduos sólidos gerados e informados. Com exceção dos resíduos de serviços de saúde, os demais tipos de resíduos são coletados diariamente por veículos e funcionários da prefeitura no centro da cidade e três vezes por semana nos demais setores, totalizando 5,1 ton/dia, sendo 4,2 ton/dia provenientes da produção de resíduos sólidos domiciliares.

No entanto, não é realizada pesagem periódica dos caminhões de coleta, o que dificulta uma maior precisão sobre a quantidade de resíduos sólidos gerados e informados. 
Segundo Bley Jr. (2001) apud Junkes (2002, p. 18), os resíduos sólidos domiciliares são compostos por uma fração orgânica que apresenta em média $50 \%$ de resíduos orgânicos de origem vegetal e animal, e aproximadamente $1 / 3$ composto de resíduo reciclável.

Além da fonte geradora domiciliar, também são gerados resíduos orgânicos no meio urbano, considerado como resíduo sólido orgânico limpo, por compor uma quantidade de resíduo homogêneo, como por exemplo, os restos vegetais gerados em podas, capinas, agroindústria, restaurantes e cozinhas industriais, entre outras.

Para Pereira (1999) apud Junkes (2002, p. 19), $90 \%$ da poluição brasileira tem origem orgânica através da disposição inadequada de resíduos sólidos orgânicos em lixões e aterros mal controlados que, a partir da putrefação, ocasiona a emanação de gases mal cheirosos e a produção de chorume, sendo este, um potencial poluidor do solo e das águas superficiais e subterrâneas.
Conscientes dos problemas ambientais ocasionados pela disposição inadequada desses resíduos sólidos, muitos municípios de pequeno porte têm buscado a solução através da reciclagem e compostagem. Nesse sentido, muitas administrações públicas e até mesmo o setor privado têm realizado a implantação de Usinas de Triagem e Compostagem de resíduos nos municípios.

Em Tarumã, os resíduos sólidos são destinados a uma Usina de Triagem e Compostagem, onde eles passam por um processo de separação, para depois serem reintroduzidos no processo industrial, permitindo a reciclagem e/ou transformação em um novo produto.

Essa Usina de Triagem e Compostagem foi criada em 1997 como um Projeto Social através da ACRUTA - Associação Comunitária do Centro Rural de Tarumã, cujos investimentos iniciais foram da ordem de $\mathrm{R} \$ 141.479,10$, conforme TAB. 1.

TABELA 1. Investimentos na implantação da Usina de Triagem e Compostagem.

\begin{tabular}{lr} 
TIPO DE INVESTIMENTO & VALOR \\
\hline Construção do Prédio Administrativo & $\mathrm{R} \$ 57.457,28$ \\
Construção da Fundação do Galpão & $\mathrm{R} \$ 30.424,06$ \\
Construção da Estrutura e Cobertura & $\mathrm{R} \$ 15.097,79$ \\
Instalação da Rede Elétrica & $\mathrm{R} \$ 11.000,00$ \\
Fornecimento de Equipamentos & $\mathrm{R} \$ 23.500,00$ \\
Fornecimento de Equipamentos & $\mathrm{R} \$ 4.000,00$ \\
TOTAL & R\$ $\mathbf{1 4 1 . 4 7 9 , 1 3}$ \\
\hline
\end{tabular}

Fonte: Secretaria de Agricultura, Abastecimento e Meio Ambiente. 2008.

A área onde atualmente funciona a Usina possui $24.200 \mathrm{~m}^{2}$ e foi adquirida através de doação feita por um produtor rural do município. Os investimentos iniciais foram realizados pela Secretaria de Assistência Social do Estado de São Paulo.

Para o seu funcionamento, atualmente a Usi- na tem um custo anual de $\mathrm{R} \$ 417.000,00$. E o valor arrecadado com a realização de 04 leilões anuais é de aproximadamente $\mathrm{R} \$ 100.000,00$. Toda essa arrecadação destina-se ao Fundo Social de Solidariedade, que o transforma em Projetos Sociais.

Ao lado da área onde funciona a Usina de Tri- 
agem e Compostagem existem as valas para disposição dos resíduos sólidos urbanos, sendo uma para a disposição dos entulhos e a outra para a disposição do rejeito proveniente do processo de Triagem e Compostagem dos resíduos.

Com uma geração de 4,2 ton/dia de resíduos sólidos domiciliares, logo após a instalação da usina
(1997), o Índice de Qualidade de Aterros de Resíduos (IQR) já passa da condição controlada para a condição adequada, na qual se mantém até 1999. No ano de 2000 seu IQR cai para 7,8, sendo classificado como controlado. Permanece desta forma até 2003 quando volta à condição adequada. No entanto, pode-se observar, conforme TAB. 2, que de 2005 a 2007 o índice de Tarumã teve uma queda de 2,4 .

TABELA 2. Índice de Qualidade de Resíduos Sólidos Domésticos em Tarumã-SP

\begin{tabular}{lccccccccccccc}
\hline Município & UGRHI & Lixo(ton/dia) & 1997 & 1998 & 1999 & 2000 & 2001 & 2002 & 2003 & 2004 & 2005 & 2006 & 2007 \\
\hline Tarumã & 17 & 4,2 & 6,3 & 8,6 & 8,1 & 7,8 & 7,8 & 7,8 & 8,0 & 8,1 & 9,2 & 8,2 & 6,8 \\
\hline
\end{tabular}

Fonte: Inventário Estadual de Resíduos Sólidos Domiciliares. CETESB, 2007.

Atualmente o aterro apresenta condições controladas, conforme IQR/IQC 2007. Mas, foi possível observar durante as visitas a campo, que as condições visuais apresentadas pelo aterro são semelhantes a um lixão a céu aberto.

\subsubsection{Os materiais recicláveis}

O processo de triagem dos materiais recicláveis compreende o despejo dos resíduos em local apropriado no início da esteira. E, conforme a esteira se movimenta os diversos tipos de resíduos são selecionados e agrupados.

No total são 22 (vinte e dois) colaboradores que trabalham na Usina de Triagem e Compostagem. Destes 22, existem atualmente 20 que prestam serviços terceirizados e 02 que são funcionários efetivos da prefeitura municipal, sendo 01 Coordenador dos Serviços realizados na Usina e 01 Supervisor de Meio Ambiente que administra a Usina.

Em Tarumã não há coleta seletiva, o que ex- põe os catadores que trabalham na Usina de Triagem e Compostagem a riscos de contaminação, no contato com o lixo. No entanto, pôde-se observar a utilização de Equipamentos de Proteção Individual (EPIs), como a máscara, a luva, o avental e o lenço na cabeça das mulheres que trabalham na esteira.

Os resíduos separados para comercialização são: sucata, alumínio, cobre, metal, antimônio, polietileno, papelão, papel comum, papel colorido, Tetra Park, saco rofi, PET, plástico filme e vidro.

A venda dos resíduos ocorre através de processo licitatório, na modalidade LEILÃO, realizado pela Prefeitura Municipal, aproximadamente 4 (três) vezes ao ano. Foram analisados os dados dispostos em dois processos licitatórios: o processo $n^{\circ} 087 / 2007$ de 27/ 08/2007 e o processo $n^{\mathrm{o}}$ 090/2008 de 24/06/2008.

O objeto das referidas licitações compreendeu o leilão dos materiais relacionados abaixo e suas respectivas quantidades: 
TABELA 3. Quantidade de resíduo gerado em Tarumã - SP edital - 02/2007 (kg).

\begin{tabular}{lr}
\hline DESCRIÇÃO & QTDE. \\
\hline Papelão & 25.000 \\
Plastico Filme & 25.000 \\
Papel Comum & 6.500 \\
Papel Colorido & 2.500 \\
Tetra Pak & 9.000 \\
Saco Rafia & 1.500 \\
Polietileno & 15.000 \\
PET & 7.000 \\
Aluminio & 300 \\
Cobre & 30 \\
Sucata de Ferro & 7.500 \\
Vidro (cacos) & 3.000 \\
\hline TOTAL & $\mathbf{1 0 2 . 3 3 0}$ \\
\hline
\end{tabular}

Fonte: Entrevista com o responsável geral pela administração da Usina: em Junho de 2007 e descrito no edital 02/2007 de leilão dos resíduos recicláveis.

De acordo com a TAB. 3 durante um período de aproximadamente três meses, foram gerados e preparados para a comercialização, um total de 102.330 kg de materiais recicláveis no município de Tarumã. Já a TAB. 4, que compreende a um período de três meses, porém, referente ao ano de 2008, apresenta a quantidade de materiais recicláveis gerados e preparados para a comercialização num total de $96.365 \mathrm{~kg}$.

TABELA 5. Tipo de resíduos separados na esteira e valor apresentado em edital para sua comercialização.

\begin{tabular}{lc}
\hline RESÍDUOS & VALOR (kg) \\
\hline Sucata de ferro & $\mathrm{R} \$ 0,25$ \\
Alumínio & $\mathrm{R} \$ 2,60$ \\
Cobre & $\mathrm{R} \$ 3,00$ \\
Metal & $\mathrm{R} \$ 2,50$ \\
Antimônio & $\mathrm{R} \$ 1,80$ \\
Polietileno & $\mathrm{R} \$ 0,30$ \\
Papelão & $\mathrm{R} \$ 0,15$ \\
Papel comum & $\mathrm{R} \$ 0,10$ \\
Saco Rafia & $\mathrm{R} \$ 0,15$ \\
PET & $\mathrm{R} \$ 0,35$ \\
Vidro (cacos) & $\mathrm{R} \$ 0,02$ \\
Tetra Pak & $\mathrm{R} \$ 0,10$ \\
Plástico filme & $\mathrm{R} \$ 0,45$ \\
Papelão colorido & $\mathrm{R} \$ 0,05$ \\
\hline Fonte: Descrito no edital $02 / 2007$ de leilão dos \\
materiais recicláveis.
\end{tabular}

Sociedade \& Natureza, Uberlândia, 21 (2): 159-179, ago. 2009
TABELA 4. Quantidade de resíduo gerado em Tarumã - SP edital - 02/2008 (kg).

\begin{tabular}{lr}
\hline DESCRIÇÃO & QTDE. \\
\hline Papelão & 12.000 \\
Plastico Filme & 23.000 \\
Papel Comum & 6.500 \\
Papel Colorido & 2.500 \\
Tetra Pak & 5.000 \\
Saco Rafia & 20.000 \\
Polietileno & 10.000 \\
PET & 5.000 \\
Aluminio & 150 \\
Cobre & 50 \\
Sucata de Ferro & 1.000 \\
Vidro (cacos) & 6.000 \\
Lata & 5.000 \\
Antimônio & 15 \\
\hline TOTAL & $\mathbf{9 6 . 3 6 5}$ \\
\hline Fonte: Prefeitura Municipal de Tarumã. Leilão. Pro- \\
cesso n ${ }^{\circ}$ 090/2008.
\end{tabular}

Sobre os valores adquiridos na venda dos resíduos recicláveis gerados em Tarumã, destacamos aqueles obtidos no LEILÃO de junho de 2007. Assim, na TAB. 5 estão relacionados os materiais recicláveis descritos no edital 02/2007. Já na TAB. 6, apresentamos os materiais recicláveis já leiloados em junho de 2007 e o valor pago pelo $\mathrm{kg}$ de cada um no leilão.

TABELA 6. Tipo de resíduos separados na esteira e valor aproximado na sua comercialização.

\begin{tabular}{lc}
\hline RESíDUOS & VALOR (kg) \\
\hline Sucata de ferro & $\mathrm{R} \$ 0,20$ \\
Alumínio & $\mathrm{R} \$ 3,00$ \\
Cobre & $\mathrm{R} \$ 3,55$ \\
Metal & $\mathrm{R} \$ 2,50$ \\
Antimônio & $\mathrm{R} \$ 5,55$ \\
Polietileno & $\mathrm{R} \$ 0,33$ \\
Papelão & $\mathrm{R} \$ 0,16$ \\
Papel comum & $\mathrm{R} \$ 0,11$ \\
Saco Rafia & $\mathrm{R} \$ 0,17$ \\
PET & $\mathrm{R} \$ 0,38$ \\
Vidro (cacos) & $\mathrm{R} \$ 0,04$ \\
Tetra Pak & $\mathrm{R} \$ 0,07$ \\
Plástico filme & $\mathrm{R} \$ 0,22$ \\
Papelão colorido & $\mathrm{R} \$ 0,02$ \\
\hline Fonte: Entrevista com o responsável geral pela ad- \\
ministração da Usina: em Junho de 2007.
\end{tabular}


Ao comparar os dados publicados em edital para leilão e os dados informados pela Secretaria de Agricultura, Abastecimento e Meio Ambiente de Tarumã, observa-se que através do leilão, para a maioria dos materiais recicláveis foram praticados valores superiores àqueles publicados no edital, com destaque para os materiais de valor mais alto.

No entanto, não há coleta seletiva na cidade de Tarumã. Fator que contribui para que os resíduos percam em qualidade na hora de sua comercialização, pois, o contato com a matéria orgânica dificulta a oferta de melhores preços nos leilões realizados para sua venda.
Também não há investimentos em campanhas educativas sobre a necessidade de separação dos resíduos sólidos domiciliares.

\subsubsection{A Usina de Produção de Açúcar e Álcool Nova América}

Um importante fator para a análise do gerenciamento dos resíduos sólidos em Tarumã é a presença da Usina de Açúcar e Álcool Nova América que doa os materiais recicláveis, papel e plástico, provenientes do seu processo de produção, para a Usina de Triagem e Compostagem de Tarumã, sistematizados no QUADRO 1.

\begin{tabular}{|l|c|c|}
\hline \multirow{2}{*}{} & \multicolumn{2}{|c|}{ RESíDUO } \\
\cline { 2 - 3 } & PAPEL & PLÁSTICO \\
\hline CLASS. NBR 10004/04 & Classe II & Classe II \\
\hline QUANT. ESTIMADA (ANUAL) & $104.860 \mathrm{~kg}$ & $105.100 \mathrm{~kg}$ \\
\hline COMP. APROXIMADA & Celulose & Res. derivadas de petróleo \\
\hline ARMAZENAMENTO & Caçamba & Caçamba \\
\hline DISPOSIÇÃO & $104.860 \mathrm{~kg}$ & $105.100 \mathrm{~kg}$ \\
\hline QUANT. TRANSP. PARA A DISPOSIÇÃO & - & - \\
\hline TRANSP. INTERNO & Us. Triagem e Compostagem de Tarumã & Semanal \\
\hline TRANSP. EXTERNO & Semanal & Uriagem e Compostagem de Tarumã \\
\hline
\end{tabular}

QUADRO 1. Materiais Recicláveis gerados na Usina Nova América - Tarumã-SP.

Fonte: Pesquisa de campo (entrevistas).

Usina Nova América - Tarumã-SP, dez / 2006.

Podemos observar no quadro 1 , que todo o papel e plástico gerado no processo de produção da Usina Nova América são destinados à Usina de Triagem e Compostagem de Tarumã. Seus valores são de aproximadamente $105.000 \mathrm{~kg}$ de papel e $105.000 \mathrm{~kg}$ de plástico por ano.

\subsubsection{Os resíduos sólidos orgânicos}

Além da separação dos materiais recicláveis na esteira de usina, também é realizado o processo de compostagem dos resíduos sólidos orgânicos coletados na cidade.
Esses resíduos são transformados em um composto orgânico utilizado para a produção de hortaliças numa Horta Municipal existente em Tarumã. Essa horta tem como principal objetivo, atender escolas, creches, e a população, de forma geral. São aproximadamente 550 famílias atendidas por mês.

Vale reforçar que a compostagem é um processo biológico de decomposição da matéria orgânica contida em restos de origem animal ou vegetal. E, como tal, resulta num produto - o composto orgânico - que pode ser adotado por indústrias e municípios para ser adicionado ao solo e melhorar suas características para uso agrícola. 
No entanto, esse composto deve ser feito a partir de um controle rigoroso da qualidade dos resíduos orgânicos visando evitar a geração de um composto com a presença de contaminantes adquiridos dos demais resíduos. (FELIPETTO, 2005; 2007, p. 21).

Nesse sentido, de acordo com a Secretaria de Agricultura e Meio Ambiente é realizado regularmente um controle dos metais pesados presentes no composto orgânico produzido na Usina de Triagem e Compostagem.

Diante do atual contexto de Tarumã, podemos identificar dentre os quatro modelos de gestão apontados por LOGAREZZI, (2004, p. 237), que, Tarumã caminha para uma Gestão na coleta de resíduos, em que se dá prioridade à cobertura de serviços de coleta de resíduos, que deve incluir a coleta comum e a coleta seletiva. No entanto, ressaltamos a importância de haver maior preocupação por parte da atual administração municipal, no tocante à coleta seletiva, ainda não implantada no município, permitindo que os materiais recicláveis percam valor de comercialização pelo contato com a matéria orgânica existente no lixo doméstico.

\subsection{Teodoro Sampaio}

No município de Teodoro Sampaio os serviços de coleta, transporte e disposição dos resíduos sólidos são realizados pela Prefeitura Municipal.

Os resíduos coletados são de tipo domiciliar, de construção civil, comercial, público, de varrição e de serviços de saúde (aqui estimados em valores mínimos), resultando num total de 11 toneladas diárias. Destes, 6,6 t/dia são provenientes de resíduos sólidos domiciliares. No entanto, não é realizada pesagem periódica dos caminhões de coleta, o que dificulta uma maior precisão sobre a quantidade de resíduos sólidos gerados.

O serviço de coleta dos resíduos sólidos não é cobrado da população e constitui $3,5 \%$ do orçamento municipal.
Destaca-se que muitos municípios não cobram pelos serviços de coleta e transporte dos resíduos sólidos. Dados brasileiros que compõem a base da primeira avaliação regional de 2002 dos serviços de manejo de resíduos sólidos municipais nos países da América Latina e Caribe demonstraram que mais de 50\% dos municípios não cobram dos seus munícipes pela execução dos serviços. A grande maioria dos municípios, em especial os de pequeno e médio portes, não possuem pessoal técnico qualificado para planejar, monitorar e avaliar os serviços e implantar sistema de custos e de cobrança pelos serviços. (MINISTÉRIO DAS CIDADES, 2003, pg. 10).

Com exceção dos resíduos de serviços de saúde, os demais tipos de resíduos são coletados diariamente por veículos e funcionários da prefeitura no centro da cidade e três vezes por semana nos demais setores.

Em Teodoro Sampaio, os resíduos sólidos são destinados a um aterro controlado. Essa forma de disposição dos resíduos sólidos constitui alternativa aceitável pelos órgãos ambientais para municípios de pequeno porte. Trata-se de local onde os resíduos devem ser depositados, compactados e recobertos diariamente por uma camada de material inerte.

Todavia, apesar da Companhia de Tecnologia de Saneamento Ambiental - CETESB (2002), em três visitas realizadas no mês de agosto de 2003, ao aterro de Teodoro Sampaio, indicar que o município possuía Índice de Qualidade de Aterros de Resíduos (IQR) classificado como adequado, os resíduos foram encontrados descobertos. Em visita realizada no mês de abril de 2004, observou-se o total preenchimento da vala utilizada no aterro e realização de acondicionamento diário dos resíduos sobre a vala já esgotada, o que impossibilitava a cobertura diária dos mesmos. Havia necessidade de abertura de uma nova vala. Em visita realizada no mês de Julho de 2004 uma nova vala havia sido aberta, no entanto, ainda apresentava irregularidades, como grande quantidade de resíduos sem cobertura e percolação de chorume.

Entre os meses de agosto de 2005 e agosto de 2007 , foram realizadas quatro visitas ao local de dis- 
posição dos resíduos para acompanhamento das condições do ambiente e das ações que estavam sendo tomadas com vistas a minimizar o impacto da disposição inadequada desses resíduos. No entanto, em todas as visitas pôde-se observar a mesma condição irregular apresentada anteriormente, com grande quantidade de resíduos sem cobertura e percolação de chorume.

Tal situação reforça nossa compreensão de que, embora o município tenha licença ambiental para aterro controlado, em determinadas épocas as condições existentes são as de um lixão a céu aberto.

Dentre as soluções que podem ser utilizadas para minimizar este tipo de problema, temos o manejo adequado do aterro em vala ou a implantação de um aterro sanitário, o qual, em determinadas situações, constitui a melhor forma de disposição dos resíduos sólidos domiciliares. No entanto, considera-se necessário a realização de um estudo mais específico para análise da viabilidade, sobretudo econômica, deste tipo de aterro para municípios de pequeno porte.

No aterro sanitário a disposição dos resíduos sólidos visa proteger o meio ambiente e saúde pública e favorecer a segurança e o bem estar da população. Para tanto, devem ser aplicadas técnicas de engenharia e normas operacionais específicas para confinar os resíduos na menor área possível e reduzir ao mínimo o seu volume, cobrindo-os com uma camada de terra ou material inerte, quantas vezes forem necessárias. $\mathrm{O}$ aterro sanitário deve ainda conter sistemas de impermeabilização da base e laterais, sistemas de drenagem do chorume, tratamento, remoção segura e queima dos gases produzidos (FEAM, 2002).

Também são destinados ao aterro controlado do município, os resíduos de serviços de saúde (RSS), compostos por material cortante, material perfurante $\mathrm{e}$ embalagens.

Esses resíduos são destinados ao aterro, e acondicionados em uma vala separada dos outros materiais. É importante enfatizar que dentre os tipos de resíduos gerados em área urbana, os RSS, mesmo que em pequenas quantidades devem receber cuidados espe- ciais pelo risco potencial que apresentam podendo ser fonte de microorganismos patogênicos, cujo manuseio, tratamento e/ou descarte inadequado podem acarretar a disseminação de doenças infecto-contagiosas. (MUÑOZ, 2002, apud LOPES, 2003, p. 5).

Outra forma de destinação dos RSS, que é utilizada por alguns municípios da região do Pontal do Paranapanema é a queima. Em Teodoro Sampaio, embora haja um incinerador dentro do hospital municipal, de acordo com a vigilância sanitária, atualmente, ele não está sendo utilizado. No entanto, os resíduos hospitalares estão sendo encaminhados para o aterro controlado, sem qualquer tratamento.

A incineração, conforme FEAM (2002) constitui-se num processo de queima dos resíduos a elevadas temperaturas $\left(800 \mathrm{a} 1.000{ }^{\circ} \mathrm{C}\right)$, até ser reduzido a cinzas, com a vantagem de reduzir os resíduos em cerca de $90 \%$, tanto em volume como em peso. Todavia, representa elevados custos de investimento inicial, de operação e de manutenção e pode ocasionar poluição atmosférica.

Em todas as visitas realizadas ao aterro também foram encontrados pneus acomodados em local sem cobertura.

Visto que os pneus reservam água das chuvas no seu interior e pode servir de criadouro de mosquito da dengue e demais vetores, constitui risco de saúde para o catador que atua no aterro, para os funcionários da prefeitura que trabalham transportando os resíduos e operando máquinas no aterro e dependendo da distância de área urbana e pequenos vilarejos, constitui risco à saúde da população em geral.

Conforme Resolução SMA/SS 1 de 05-3-2002, os pneus são classificados como resíduos inertes, o que permite sua disposição em aterros, desde que observadas as técnicas para o seu adequado manejo,:

Art. $1^{\circ}$ - A disposição final de pneus em aterros sanitários condiciona-se, cumulativamente, à:

I - prévia descaracterização do pneu, median- 
te tritura ou retalhamento do qual resultem apenas partes insuscetíveis de acumular águas ou outros líquidos;

II - prévia mistura dessas partes com os resíduos domiciliares ou ao seu espalhamento sobre estes, de forma a haver proporcionalidade entre ambos os resíduos, para a garantia da estabilidade do aterro.

Cabe destacar que, além de não haver na cidade de Teodoro Sampaio a descaracterização dos pneus previamente à sua disposição, no processo que autoriza o funcionamento do aterro em vala, consta que este local é destinado exclusivamente para a disposição de resíduos domiciliares, não podendo, portanto, haver qualquer outro tipo de resíduo.

Quem fiscaliza a situação da destinação dos resíduos sólidos na região do Pontal do Paranapanema é a Companhia de Tecnologia de Saneamento Ambiental (CETESB) que, criada em 24 de julho de 1968 pelo Decreto ${ }^{\circ} 50.079$, tem como responsabilidade o controle, a fiscalização, o monitoramento e o licenciamento de atividades geradoras de poluição, tendo como preocupação fundamental preservar e recuperar a qualidade das águas, do ar e do solo (CETESB, 2002).

A partir de 1996, esta Companhia começou um trabalho de conscientização com os prefeitos municipais dessa região visando a regularização das condições de destinação dos resíduos sólidos. Hoje, atua em visitas periódicas, sem período definido, para não permitir que as prefeituras preparem cenários para receber a fiscalização. $O$ processo se dá mediante visita aos aterros e/ou lixões existentes na região, de acordo com a condição observada no acondicionamento, transporte e/ou disposição final dos resíduos. Caso estejam inadequadas, as prefeituras são advertidas. Com a manutenção dos fatos, as prefeituras são multadas, com o objetivo principal de pressionar os municípios para que regularizem sua situação.

Teodoro Sampaio, em setembro de 1997, a CETESB realizou inspeção no município e diagnosticou a necessidade de melhorias quanto à disposição dos resíduos sólidos. Nesse período os resíduos também eram descartados no local onde hoje funciona o aterro em valas, que já mantinha características de lixão.

Conforme CETESB (2002) o IQR apresentado pelo município em 1997 foi inadequado. Em março de 1998 a CETESB apresentou advertência para o município, e em setembro de 1998 multou a prefeitura. Nesse período, para todos os municípios que apresentavam irregularidades na destinação dos resíduos sólidos, foi proposta a assinatura do Termo de Ajustamento de Conduta (TAC), que é um título executivo extrajudicial estabelecido em comum acordo com as administrações municipais, definindo prazos e atividades a serem realizadas pelo município, para regularização ambiental das instalações de disposição de resíduos em operação (CETESB, 2003).

Em março de 1998, a Prefeitura de Teodoro Sampaio assinou o TAC. Desse momento em diante, houve certo avanço quanto à disposição dos resíduos sólidos no município. Mas foi somente em fevereiro de 2002 que a licença de operação do aterro controlado foi concedida (CETESB, 2003).

No ato da concessão da licença o aterro estava mantendo satisfatórios resultados relativos ao Índice de Qualidade de Resíduos Sólidos Domésticos. E manteve bons resultados nos anos de 2003, 2004 e 2005, caindo para condição inadequada em 2006. E em 2007 o aterro apresentou condições adequadas, conforme IQR 2007. (TAB. 7).

TABELA 7. Índice de Qualidade de Resíduos Sólidos Domésticos em Teodoro Sampaio

\begin{tabular}{|c|c|c|c|c|c|c|c|c|c|c|c|c|c|}
\hline Município & UGRHI & Lixo (ton/dia) & 1997 & 1998 & 1999 & 2000 & 2001 & 2002 & 2003 & 2004 & 2005 & 2006 & 2007 \\
\hline $\begin{array}{l}\text { Teodoro } \\
\text { Sampaio }\end{array}$ & 22 & 6,6 & 3,6 & 3,7 & 5,2 & 4,8 & 7,5 & 8,7 & 7,5 & 8,6 & 7,8 & 5,2 & 8,2 \\
\hline
\end{tabular}

Fonte: Inventário Estadual de Resíduos Sólidos Domiciliares. CETESB, 2007. 
De propriedade da Prefeitura Municipal, durante o período de 2001 a 2007, o aterro controlado esteve em funcionamento localizado no km-3 da Rodovia SPV-31, ocupando uma área em torno de 24.200 $\mathrm{m}^{2}$. Sua vida útil foi projetada, conforme CETESB (2003), para 10 anos, mas antes mesmo de completar esse período, o aterro já havia se esgotado por completo, e no início de 2007 o local de abertura da primeira vala, já estava sendo novamente utilizada para disposição de resíduos.

O aterro foi calculado para uma população de 10.000 habitantes, considerando a população urbana visto que somente na área urbana são coletados os resíduos. Porém, conforme contagem do IBGE (2006), a população já aumentou para 16.318 pessoas, além dos hábitos da população permitir uma geração cada vez maior de resíduos em suas atividades diárias, contribuindo assim, para que as áreas de disposição dos resíduos se esgotem com mais rapidez.

Por se tratar de um aterro controlado, deve-se enfatizar que o local não possui impermeabilização do solo, condição necessária para impedir que o chorume, líquido proveniente da decomposição da matéria orgânica em contato com as águas das chuvas, infiltre no solo, contaminando cursos d'água e águas subterrâneas.

Mas, de acordo com a Secretaria de Meio Ambiente da Prefeitura Municipal de Teodoro Sampaio, foi realizada uma sondagem para verificar o nível do lençol freático. Foram escavados 6 metros de profundidade não chegando ao lençol. Também não há corpos d'água nem construções urbanas (residências, escolas, entre outros) no entorno do local.

Conforme Resolução Conama nº 308 de 2002, "a área selecionada para implantação do sistema de disposição final dos resíduos sólidos deve ser isolada com cerca, impedindo a entrada de pessoas não autorizadas e de animais".

No entanto, a área do aterro não representa incômodo para a visinhança, pois, está localizada distante da área urbana da cidade e contornada por pastagens.
Atualmente, a Prefeitura Municipal está negociando a compra de uma área ao lado do aterro já esgotado. Mas, antes mesmo de possuir licença para funcionar, o atual aterro já está recebendo diariamente resíduos na forma de lixo.

Para a disposição desses resíduos na vala atual, os caminhões da prefeitura precisam percorrer toda a extensão do antigo aterro. Ressalta-se que, uma área de aterro recentemente encerrada não deveria receber sobrecarga de peso, pois pode haver rebaixamento do terreno, o que coloca em risco a segurança das pessoas que trabalham no local.

\subsubsection{Ações em busca do Gerenciamento Integrado dos Resíduos Sólidos}

Na Lei Orgânica Municipal não são especificados os devidos cuidados necessários com os resíduos sólidos gerados.

No entanto, foi implantada recentemente a Lei Municipal Complementar $\mathrm{n}^{\circ} 21$ de outubro de 2006 que dispõe sobre o Plano Diretor do Município. Em seu art. $3^{\circ}$ item XIII declara que a política de desenvolvimento e expansão urbana de Teodoro Sampaio visa assegurar o aprimoramento dos serviços de limpeza urbana, coleta, tratamento e disposição, inclusive mediante a implantação de programas de coleta seletiva de resíduos e programas educativos.

E, nessa perspectiva, foi elaborado pela Secretaria do Meio Ambiente do município, um projeto para implantação da coleta seletiva, cujos objetivos principais são: viabilizar destinação alternativa para os resíduos; sensibilizar a comunidade, por meio da educação ambiental, para a prática da cidadania; viabilizar a coleta seletiva no município e organizar os catadores existentes para um adequado gerenciamento dos resíduos sólidos; orientar a população a separar os resíduos no local de origem; propiciar geração de emprego e renda aos catadores; e transformar os catadores em agentes ambientais visando o desenvolvimento social e ambiental do município.

O Projeto de Coleta Seletiva em Teodoro Sam- 
paio faz parte de um Programa de Gerenciamento Integrado de Resíduos Sólidos Urbanos que tem por objetivo atender às diretrizes do Plano Diretor e Saneamento do Município. Deve-se considerar que a coleta seletiva está prevista na Lei Complementar $\mathrm{n}^{\circ} 21 \mathrm{de}$ 10/10/06.

Na descrição do Projeto prevê-se que o Programa de Coleta Seletiva terá início como experiência piloto no Conjunto Habitacional Ulisses Guimarães, eleito por seu pequeno tamanho.

É importante ressaltar que em 2005 foi realizado um Diagnóstico dos Resíduos Sólidos em Teodoro Sampaio, por esta autora que, em poder da Secretaria Municipal de Meio Ambiente, vem sendo utilizado para apoiar as tomadas de decisão quanto à implantação da coleta seletiva na cidade.

Essa pesquisa foi realizada com a população moradora de todos os bairros de Teodoro Sampaio para análise da aceitação popular quanto à implantação de coleta seletiva. Durante a pesquisa foram considerados fatores como: o acesso ao conhecimento do processo de descarte e coleta seletivos dos resíduos sólidos domiciliares, conhecimento do local onde os resíduos na forma de lixo são depositados e avaliação da importância e aceitabilidade da população em descartar os resíduos separadamente. Os resultados demonstraram que $57 \%$ da população não conhecem ter- mos como coleta seletiva e materiais recicláveis, 24\% não conhece o local onde os resíduos são depositados e $85 \%$ da população considera importante para o meio ambiente participar do descarte seletivo dos resíduos. Essas informações ajudaram a elaborar e justificar a importância de um projeto para implantação da coleta seletiva na cidade de Teodoro Sampaio-SP.

Com base nessa experiência, o sistema deverá ser ampliado gradativamente para os demais bairros.

Entre as ações de planejamento realizadas em Teodoro Sampaio para implantação da coleta seletiva, foram identificados os melhores pontos para instalação de 16 recipientes coletores de resíduos de 50 litros, adquiridos através de parcerias com segmentos do comércio local, indústrias e ONG's. Dentre eles, 10 já foram entregues e estão aguardando para serem colocados nos locais planejados.

Recentemente, em agosto de 2008, Teodoro Sampaio adquiriu um novo caminhão coletor de resíduos através de um convênio com a Secretaria Estadual de Meio Ambiente (SEMA).

De acordo com os dados informados pela Secretaria Municipal de Meio Ambiente, estão previstos gastos para a instalação de uma Cooperativa de Catadores em Teodoro Sampaio, conforme a TAB. 8:

TABELA 8. Gastos previstos para a instalação da Cooperativa de Catadores em Teodoro Sampaio-SP.

\begin{tabular}{|c|c|}
\hline DESTINAÇÃO DOS GASTOS & VALORES \\
\hline Equipamentos & $\mathrm{R} \$ 232.441,00$ \\
\hline Galpão & $\mathrm{R} \$ 80.000,00$ \\
\hline Caminhão & $\mathrm{R} \$ 120.000,00$ \\
\hline TOTAL & R\$ 432.441,00 \\
\hline
\end{tabular}

Fonte: Secretaria de Meio Ambiente. 2008.

Além disso, foram visitados quatro galpões para escolha de um local para implantação de uma Cooperativa de Catadores. A área identificada como mais adequada foi o antigo Clube Pontal, situado próximo ao centro da cidade. Entre os parâmetros utilizados para a escolha da área foram considerados, as estruturas já existentes e o espaço a ser ocupado. 
Considerando a educação ambiental como uma importante estratégia de intervenção da gestão municipal, a Prefeitura Municipal vem realizando atividades de sensibilização da comunidade escolar quanto a coleta seletiva, através de palestras, e do fornecimento de recursos para separação do lixo nas escolas, tais como recipientes diferenciados, material gráfico, filmes, etc.

A efetivação do referido projeto já conta com os seguintes parceiros: departamentos e divisões da Prefeitura Municipal; Faculdade de Ciências e Tecnologia/UNESP, campus de Presidente Prudente; Sabesp; Banco do Brasil e Bradesco; Laticínio Vale do Pontal; Destilaria Alcídia; Elektro; IPÊ - Instituto de Pesquisas Ecológicas; Gráfica Gonçalves; e ACITS Associação Comercial e Industrial de Teodoro Sampaio.

Diante desse contexto, podemos identificar dentre os quatro modelos de gestão apontados por LOGAREZZI, (2004, p. 237), que Teodoro Sampaio caminha para uma Gestão na coleta de resíduos, em que se dá prioridade à cobertura de serviços de coleta de resíduos, que deve incluir a coleta comum e a coleta seletiva. Havendo também a preocupação, no tocante à coleta seletiva, de incorporar os catadores favorecendo sua organização em associações ou cooperativas.

\section{OTRABALHOCOMMATERIAIS RECICLÁVEIS EM TARUMÃ E TEODORO SAMPAIO}

A atividade de catação e separação de resíduos recicláveis pode acontecer de três tipos. O mais conhecido é o dos trabalhadores catadores carrinheiros, que percorrem as ruas da cidade empurrando carrinhos de mão, catando resíduos e encaminhando-os a depósitos no perímetro urbano. (GONÇALVES, 2005, pg. 33).

Geralmente os catadores estão ligados a um dono de depósito de resíduos, que empresta a ele, um carrinho para coleta, sua principal ferramenta de trabalho. Esses catadores, por não terem onde armazenar os resíduos, e também pela necessidade financeira, costumam realizar a venda dos resíduos diaria- mente. (LEGASPE, 1996 apud GONÇALVES, 2005, pg. 34).

Outra forma de trabalho na catação e separação dos resíduos recicláveis é aquela realizada diariamente nos lixões. A organização de catadores nos lixões vai depender, entre outros fatores: da quantidade de catadores envolvidos; da quantidade de resíduos gerados no município; e das ações do poder público no processo de coleta, transporte e disposição dos resíduos sólidos nos aterros. (GONÇALVES, 2005, pg. 34).

E, por fim temos como alternativa, a forma de trabalho com os resíduos, que considera o descarte e coleta dos resíduos, e geralmente são realizadas por Cooperativas e Associações de catadores. Esta forma de trabalho funciona com mais sucesso, se houver um Programa de Descarte e Coleta Seletivos.

Para Gonçalves, (2005, pg. 34), a principal diferença entre esta e as outras formas citadas, anteriormente, está no campo do planejamento. Segundo o autor, as três formas de coleta de resíduos aqui apresentadas não se excluem, e sim, coexistem em alguns municípios.

O trabalho de recuperação e separação dos materiais recicláveis em Tarumã e Teodoro Sampaio, que visa prioritariamente à comercialização para a industrialização, se apresenta de forma diferenciada, perpassando as três formas apresentadas acima. Ou seja, o trabalho nas ruas, no lixão e não necessariamente numa cooperativa ou associação, mas numa Usina de Triagem e Compostagem, como é o caso de Tarumã.

O trabalho com resíduos envolve tanto homens quanto mulheres. Nos dois municípios foi possível constatar que os trabalhadores que atuam na separação e recuperação de resíduos recicláveis são predominantemente do sexo masculino, ou seja, $61 \%$. No entanto, quando observamos, separadamente, os casos de Teodoro Sampaio, e Tarumã, percebemos neste último, uma porcentagem mais expressiva de trabalhadores do sexo feminino do que em Teodoro Sampaio. 
Em Tarumã as atividades relativas aos resíduos são realizadas, em sua totalidade, numa Usina de Triagem e Compostagem. Tal condição permite tanto aos homens quanto às mulheres a realização de atividades que num determinado momento requeira o uso da força braçal e em outro momento não, permitindo momentos de descanso físico entre uma atividade e outra. Já em Teodoro Sampaio as atividades relativas à catação são realizadas predominantemente nas ruas e no aterro, o que exige maior aplicação da força física do trabalhador. Essa necessidade de empurrar carrinhos pesados, contendo os resíduos coletados pode se caracterizar como um dos motivos que dificulta a realização desta atividade pelas mulheres.

Em Teodoro Sampaio, onde os trabalhadores catadores trabalham nas ruas e no aterro existem 53\% de catadores com tempo de trabalho na catação de 1 a 3 anos e $74 \%$ com mais de 3 anos de trabalho. Já em Tarumã, são $21 \%$ dos trabalhadores com menos de 1 ano de trabalho, e que nunca trabalharam como catadores, $21 \%$ de trabalha de 1 a 3 anos na Usina de Triagem e Compostagem, havendo entre esses, 2 trabalhadores que nunca trabalharam como catadores e $58 \%$ dos catadores com mais de 3 anos de trabalho com os resíduos recicláveis, sendo todos ex-catadores.

Em Tarumã 100\% dos trabalhadores realizam suas atividades com a separação dos resíduos na Usina de Triagem e Compostagem durante um período de 8 horas por dia.

Já em Teodoro Sampaio, principalmente por conta da informalidade, há uma atuação menos organizada, chegando a 77\%, a quantidade de trabalhadores que realizam suas atividades na catação por mais de 8 horas diárias.

Durante a pesquisa foram identificados três locais distintos para a realização do trabalho de recuperação e separação dos materiais recicláveis, sendo eles, o Galpão de Triagem, para aqueles que trabalham na Usina de Triagem e Compostagem de Tarumã, com $42 \%$ dos trabalhadores entrevistados; as ruas da cidade, para aqueles que trabalham coletando resíduos nas ruas em Teodoro Sampaio, compondo 56\% de catadores; e o aterro controlado, local onde se encontra apenas um catador, realizando suas atividades diárias de sol a sol, todos os dias da semana.

No entanto, apesar das precárias condições apresentadas para a realização de suas atividades em meio aos resíduos dispostos na forma de lixo no aterro como, por exemplo, a não utilização de equipamentos de proteção individual (EPIs) e a permanência de aproximadamente 12 horas em local desprovido de condições sanitárias de trabalho, esse catador já recusou emprego na área de limpeza pública da prefeitura. E, em recente contato com a Secretaria de Obras e de Transportes para discutir a implantação da coleta seletiva na cidade, também já se manifestou contra sua saída do aterro. Seu principal argumento se sustenta no fato de atualmente adquirir renda superior àquela proposta pela prefeitura para trabalhar na varrição das ruas da cidade. E quando questionado a trabalhar numa cooperativa de catadores, informou não acreditar que a prefeitura queira oferecer valor equivalente àquele adquirido com a venda dos resíduos de ele sozinho coleta.

Quanto ao processo de comercialização dos resíduos recicláveis em Teodoro Sampaio, por se tratar de atividade em que normalmente o catador repassa grande parte dos lucros para o sucateiro, acredita-se que os lucros obtidos tanto pelos catadores como pelo sucateiro deveriam ser menores que os lucros obtidos em Tarumã com a prática do leilão. No entanto, alguns resíduos comercializados em Teodoro Sampaio se apresentam com valores ainda maiores que aqueles comercializados em Tarumã.

O papelão, por exemplo, é leiloado em Tarumã por R $\$ 0,16$ o kg, enquanto que em Teodoro Sampaio ele foi vendido pelo catador ao atravessador pelos mesmos $\mathrm{R} \$ 0,16$ o kg, e repassado para a indústria de reciclagem por R $\$ 0,22 \mathrm{o} \mathrm{kg}$. Outro exemplo é o alumínio que foi leiloado em Tarumã por $\mathrm{R} \$ 3,00 \mathrm{o} \mathrm{kg}$, e em Teodoro Sampaio ele foi vendido pelo catador ao atravessador pelos mesmos $\mathrm{R} \$ 3,00 \mathrm{o} \mathrm{kg}$, e repassado para a indústria por $\mathrm{R} \$ 4,00 \mathrm{o} \mathrm{kg}$.

Para ZANIN, M.; SILVA, L.; CORREIA, T, 
S. (2006, não paginado), os sucateiros possuem boa infra-estrutura para o manuseio e negociação dos resíduos, esses sucateiros conseguem melhores condições de negociação par os seus resíduos, pois podem esperar um melhor tempo para a venda (quando houver menor oferta ou maior preço), diferentemente das cooperativas que precisa mensalmente distribuir os seus ganhos. Muitas vezes o sucateiro consegue agregar valor realizando algumas exigências do cliente como, quantidade e qualidade dos resíduos.

No entanto, até mesmo na Usina de Triagem e Compostagem de Tarumã, por se tratar de resíduos que chegam todos misturados, provenientes da coleta comum na cidade, muitos materiais têm seu valor desagregado, uma vez que foi contaminado pelo contato com o resíduo sólido orgânico antes de chegar à usina.

Quanto aos rendimentos, 53\%, dos trabalhadores de Tarumã informou obter uma renda mensal familiar da faixa entre 2 e 3 salários mínimos. Já em Teodoro Sampaio 53\% dos catadores informou obter uma renda mensal de até 1 salário mínimo por mês e $74 \%$ informou conseguir com as atividades na catação obter uma renda na faixa entre 1 e 2 salários mínimos.

As diferenças entre os rendimentos informados pelos trabalhadores com materiais recicláveis em Teodoro Sampaio podem ser explicadas por vários fatores, como por exemplo, o tempo de trabalho com os resíduos, a quantidade de horas trabalhadas por dia, o tipo de material coletado, a área da cidade onde realiza a coleta, a condição física e de saúde do catador, a geração de resíduos na cidade, entre outros.

\section{CONCLUSÕES E RECOMENDAÇÕES}

O estudo realizado neste trabalho teve como principal objetivo analisar a gestão dos resíduos sólidos urbanos nas cidades de Tarumã e Teodoro Sampaio-SP e propor ações para o gerenciamento integrado desses resíduos.

Com o desenvolvimento da pesquisa pôde-se constatar que, ao longo desta última década, a gestão dos resíduos sólidos urbanos nos dois municípios apre- sentou algumas conquistas, por exemplo: - em Tarumã, com a implantação da Usina de Triagem e Compostagem, houve a regularização da área onde são dispostos os resíduos, a redução dos resíduos que chegam até o aterro e a inexistência de catadores nas ruas e no aterro controlado;

- em Teodoro Sampaio, os avanços referentes à gestão dos resíduos sólidos urbanos referemse à regularização de uma área para disposição dos resíduos sólidos urbanos e às medidas que vêm sendo adotadas visando a implantação de coleta seletiva e a organização de uma cooperativa de catadores para a reciclagem dos resíduos sólidos na cidade.

Foi possível diagnosticar, também, que os procedimentos utilizados atualmente para gerir os resíduos sólidos urbanos ainda necessitam de muitos investimentos, que devem ser realizados considerando o diagnóstico da atual situação dos resíduos nesses municípios e as novas perspectivas de gerenciamento integrado dos resíduos, a exemplo das recomendações aqui apresentadas.

Dessa forma, destacamos que a realização desta pesquisa, a partir do levantamento e sistematização de dados e informações sobre a atual situação dos resíduos nesses municípios, com destaque para os resíduos sólidos domésticos, pode constituir uma etapa e contribuição inicial para o gerenciamento integrado dos resíduos sólidos urbanos. Para tanto, ressaltamos, a seguir, os pontos que consideramos de maior relevância, os quais devem ser analisados, mantidos ou aprimorados como experiências para os municípios.

Para gerenciar os resíduos sólidos urbanos dessas cidades de forma integrada deve-se compreender a importância da existência de um colegiado que estabeleça as políticas públicas a serem seguidas pelos órgãos que realizam, preferencialmente de forma conjunta, os serviços de limpeza pública e de destinação, como acondicionamento, coleta, transporte e disposição em aterros, e também o descarte e coleta seletivos, visando garantir seus benefícios ambientais, sociais e econômicos. 
Há necessidade, portanto, de composição de um Conselho Municipal de Gerenciamento Integrado de Resíduos Sólidos Urbanos, formado por representantes do poder público, do setor privado e da comunidade. Tal conselho deve ser normativo, deliberativo, consultivo e fiscalizador das questões ligadas ao gerenciamento integrado dos resíduos sólidos e das questões de proteção ambiental. (SAVI, 2005, p. 169).

Em Tarumã, as questões relativas aos resíduos sólidos são gerenciadas pela Secretaria de Obras e pela Secretaria da Agricultura, Abastecimento e Meio Ambiente. Já em Teodoro Sampaio, existem a Secretaria de Obras e Transporte e a Secretaria de Meio Ambiente, que dividem responsabilidades quanto ao gerenciamento dos resíduos sólidos urbanos. Nesse sentido, para a composição do Conselho, o Poder Público poderá indicar técnicos que já atuam nessas Secretarias.

Para a indicação de representantes do Setor Privado para a composição do Conselho Municipal para o GIRS, deve-se considerar as maiores empresas geradoras de resíduos, que já fazem o gerenciamento em suas próprias dependências. Como exemplo, temos a Usina Nova América, que possui um Sistema de Gerenciamento dos Resíduos provenientes da produção de açúcar e álcool, e destina grande quantidade dos resíduos recicláveis para a Usina de Triagem e Compostagem de Tarumã.

Neste caso, deve-se aproveitar também, a estrutura já existente na Usina Nova América para a prática da conscientização da população com atividades de educação ambiental.

Outro seguimento de importante participação no Conselho podem ser as Organizações Não-Governamentais (ONGs) existentes nos municípios, cuja atuação seja voltada para a preservação ambiental. Além destes, deve haver também outros representantes da sociedade como, por exemplo, das escolas públicas e privadas, associações de moradores, sindicatos, associação comercial, entre outros. (SAVI, 2005, p. 170). $\mathrm{O}$ autor ressalta a importância de todos esses seguimentos terem representação no Conselho Municipal para que possa haver seu efetivo envolvimento no GIRS do município.

Dentre as competências de um Conselho Municipal para o GIRS, destacam-se conforme Savi (2005, p. 171) e Mesquita Jr. (2007, p. 27): elaboração das diretrizes da política municipal de RSU, com planos e projetos quanto ao gerenciamento e destinação adequados; estabelecimento de normas técnicas e padrões para o correto descarte dos resíduos, acondicionamento e destinação, visando a saúde da população e a preservação do ambiente, atendendo à legislação federal, estadual e municipal; participação conjunta do Poder Executivo e Legislativo na definição, elaboração e implementação de leis de resíduos sólidos; elaboração e implementação de legislação facilitadora de beneficiamento de materiais recicláveis e de uso de materiais reciclados; definição de áreas prioritárias para atuação dos seguimentos necessários à melhoria do gerenciamento dos resíduos sólidos no município; realização de estudos com vistas a identificar as conseqüências ambientais de projetos públicos e privados, realizando intervenções e solicitando das entidades envolvidas, informações, quando julgar necessárias; elaboração e implementação de legislação e organização para a inclusão social dos catadores; desenvolvimento de ações educacionais visando sensibilizar a população sobre a importância da prática dos 4 R's (Reduzir, Reutilizar, Reciclar e Reeducar), objetivando a conscientização da população quanto à preservação ambiental; formulação e aprovação do seu próprio Regimento Interno; organização periódica de eventos relativos ao Gerenciamento Integrado de Resíduos Sólidos, como, congressos, conferências, simpósios, seminários e encontros; e decisões sobre a aplicação dos recursos destinados ao Fundo Municipal do GIRS. Neste último item, destaca-se a importância da criação de um Fundo Municipal para o desenvolvimento de atividades de educação ambiental e ações integradas ao GIRS.

Outra conclusão importante desta pesquisa refere-se à necessidade do Poder Público Municipal ter papel de destaque no tema. Assim, todas as Secretarias Municipais e órgãos municipais devem ser envolvidos no Gerenciamento Integrado dos Resíduos Sóli- 
dos no município, realizando, especialmente, o descarte seletivo de seus resíduos.

Como recomendação, apresentamos algumas propostas para atuação de algumas secretarias:

\section{- Secretaria de Obras e Meio Ambiente}

Numa proposta de gerenciamento integrado de resíduos sólidos é importante que a Secretaria de Obras e Meio Ambiente assumam a responsabilidade de coordenar a implantação da coleta seletiva no município, tendo como principal objetivo recolher os resíduos e encaminhar para a reciclagem ou reutilização, devendo para tanto, ser precedida de um descarte seletivo. Esse processo poderá ser realizado em cada domicílio ou através dos Postos de Entrega Voluntária de Resíduos (PEVs), instalados em pontos estrategicamente selecionados para melhor atender a população, que possa levar os resíduos previamente separados. (SAVI, 2005, p. 180).

É importante enfatizar que, se esse descarte ocorrer de maneira adequada e seletiva, pode facilitar as próximas etapas de coleta e triagem não permitindo que ocorra desagregação de valor ao resíduo, evitando sua contaminação. (ZANIN, M.; SILVA, L.; CORREIA, T, S., 2006, não paginado).

O passo seguinte deve ser a coleta seletiva organizada por dias determinados e por setores de coleta na cidade. Previamente separados, e estocados em alguns pontos pré-estabelecidos, os resíduos poderão ser coletados por caminhões da Prefeitura para seguir diretamente às centrais de triagem, onde os catadores terão que preparar os resíduos para serem comercializados e seguirem para as indústrias de reciclagem.

É importante também que os resíduos sólidos orgânicos sigam para pátios de compostagem, e somente os rejeitos, ou seja, resíduos que não possuem potencial de recuperação sejam destinados ao aterro controlado do município.

Além disso, é preciso evitar atravessadores, para que se possa melhorar a renda dos catadores. Para tanto, é preciso buscar investimentos financeiros para a aquisição de maquinários, como por exemplo, de pesagem e de prensagem.

De acordo com ZANIN, M.; SILVA, L.; CORREIA, T, S. (2006, não paginado), para garantir a sustentação econômica da reciclagem, é importante considerar alguns fatores, como: custo da separação, coleta, transporte, armazenamento e preparação do resíduo antes do processamento; quantidade de resíduos disponíveis e condições de limpeza; proximidade da fonte geradora em relação ao local de reciclagem do resíduo; custo de processamento do produto; características e aplicações do produto resultante; e demanda do mercado para o resíduo reciclado.

Mas, deve ficar claro que a reciclagem não pode ser considerada como uma solução definitiva para o problema dos resíduos sólidos. Deve-se entender que a solução depende de atitudes muito mais abrangentes que considerem abordagens de minimização dos resíduos na fonte geradora e reutilização de produtos e embalagens. Somente depois de esgotadas essas opções, os resíduos deverão ser reciclados para que dessa forma a disposição em aterros seja a menor possível. (ZANIN, M.; SILVA, L.; CORREIA, T, S., 2006, não paginado).

\section{-A Secretaria de Promoção Social}

Esta secretaria deverá realizar programas sociais de apoio e valorização dos catadores que já sobreviviam da catação antes da implantação da coleta seletiva.

Para tanto, deve haver a retirada de catadores que trabalhem em condições precárias e sua incorporação em uma organização de trabalhadores relacionados à coleta seletiva. Também se deve realizar uma negociação de iniciativa da Prefeitura para integração dos catadores no processo de triagem dos resíduos.

Dentre as opções podemos destacar a organização dos catadores em associações e/ou cooperativas. Outra opção seria a criação de ONGs, buscando 
evitar encargos trabalhistas, a Lei de Licitações e as mudanças políticas.

Não podemos deixar de enfatizar que o catador conhece bem os resíduos, sua classificação, o valor que cada um possui, além de ser um potencial educador ambiental no processo de implantação da coleta seletiva na cidade. No entanto, é preciso prepará-lo para esta nova fase, promovendo a sua capacitação profissional. Tal capacitação poderá se dar através de convênios com instituições educacionais como o SENAI, SEBRAE, por exemplo.

Em Teodoro Sampaio a Secretaria de Promoção Social juntamente com a Secretaria de Obras e Meio Ambiente em 2004 realizou um trabalho de orientação junto aos catadores que viviam no aterro, sobre os problemas de saúde e de segurança a que estavam submetidos em suas atividades diárias. E, na tentativa de afastá-los do aterro ofereceu-lhes emprego na área de limpeza pública da cidade. Como resultado desta ação, dos 11 catadores que viviam das atividades no aterro, 10 aceitaram o emprego, ficando somente um catador no aterrro. No entanto, distantes do aterro, mas, nas ruas da cidade ainda existem 26 trabalhadores que vivem coletando materiais recicláveis para vender aos sucateiros e garantir o sustento de suas famílias.

\section{- A Secretaria de Educação}

A principal atividade da Secretaria da Educação deverá ser a de apoiar os projetos de Educação Ambiental relacionados aos Resíduos Sólidos. Enfatizamos aqui, a importância de promover a conscientização dos alunos, professores e da população através da realização de atividades de Educação Ambiental, que proponham a redução do consumo, a reutilização e a reciclagem dos resíduos. Pois, o sucesso de todo o sistema proposto dependerá muito do grau de conscientização da população.

É necessário envolver todas as escolas no processo de implantação da coleta seletiva através de palestras, debates, aulas práticas de orientação sobre como e por que dispor os resíduos adequadamente, oficinas de reutilização de materiais recicláveis, entre outras ações. Deve-se ressaltar que quando o aluno desenvolve a consciência ambiental torna-se um importante aliado do Poder Público na orientação de seus familiares e amigos quanto à necessidade do descarte seletivo de materiais recicláveis.

A conscientização dos moradores pode ocorrer por meio da distribuição de folhetos explicativos e conversas com a população no sentido de orientar quanto a importância da prática de reciclagem dos resíduos. Além disso, vários programas de coleta seletiva já existentes costumam, além de entregar folhetos e conversar com a população, distribuir sacos de resíduos para que as pessoas já possam iniciar sua separação na própria residência.

Em Teodoro Sampaio, estão sendo desenvolvidas ações de orientação quanto ao descarte seletivo, visando a conscientização da população por meio de Palestras Escolares desenvolvidas em todas as escolas públicas e privadas do município. Esta ação precede a implantação da coleta seletiva em todos os bairros da cidade, prevista para iniciar em outubro de 2008, como projeto piloto, no Conjunto Habitacional Ulisses Guimarães, conforme descrito anteriormente.

Já em Tarumã, as atividades educativas são realizadas periodicamente pela Usina de Produção de Açúcar e Álcool Nova América com seus funcionários e visitantes. Destaca-se a necessidade de implantação da coleta seletiva no município, o que permitiria à Usina de Triagem e Compostagem trabalhar com resíduos mais limpos, e realizar melhores negociações na venda do produto. Além de minimizar os riscos de contaminação e também de acidentes provenientes do contato direto do trabalhador com os resíduos recicláveis descartados como lixo.

\section{- A Secretaria de Saúde}

A Secretaria de Saúde deve promover condições para o acondicionamento, armazenamento e descarte dos RSS seguindo as normas técnicas necessárias. Para tanto, deverá realizar cadastro de todos os estabelecimentos que geram RSS e propor e implantar 
melhorias para o adequado controle de todo o sistema de geração, acondicionamento e descarte desses resíduos. Outro procedimento que deve ser realizado diz respeito à conscientização dos proprietários de estabelecimentos que prestam serviços de saúde quanto ao adequado acondicionamento e armazenamento dos RSS, que pode ser realizado em parceria com a secretaria de educação.

Nos municípios de Tarumã e Teodoro Sampaio, os RSS são dispostos em vala separada dos demais resíduos no aterro controlado. Mesmo assim, torna-se necessária a periódica fiscalização das condições dessas valas sépticas e orientações aos funcionários do local quanto à importância e obrigatoriedade de utilização de equipamentos de segurança para o manejo desses resíduos.

\section{-A Secretaria de Finanças}

A Secretaria de Finanças é extremamente importante para o sucesso de um Programa de Gerenciamento Integrado de Resíduos Sólidos. É por meio dela que se deve viabilizar os investimentos necessários, como a compra de máquinas, investimentos em propaganda, entre outros. Assim, tanto em Tarumã como em Teodoro Sampaio devem ser incluídos no orçamento municipal anual, verbas destinadas ao desenvolvimento dos programas de GIRS.

\section{-A Secretaria de Planejamento}

De extrema importância durante todo o processo de implantação do GIRS, definindo os pontos estratégicos nos quais cada secretaria deverá atuar, cabe ao planejamento desenvolver ações que auxiliem na implantação e adequação da coleta seletiva com a coleta regular, considerando qualidade e produtividade com o mínimo de custo possível.

Até o presente momento as cidades de Teodoro Sampaio e Tarumã apresentam somente a coleta comum. Nesse sentido, faz-se necessária a realização de um levantamento de informações que possam determinar o volume e peso dos resíduos domésticos coletados diariamente para que se possa realizar uma reorganização da coleta comum e implantação da coleta seletiva.

Após a implantação da coleta seletiva deve haver avaliação periódica do desempenho operacional da coleta dos resíduos.

Quanto aos avanços relativos ao processo de implantação do projeto de coleta seletiva, ocorridos em 2008 em Teodoro Sampaio, podemos citar a aquisição de um novo caminhão coletor adquirido através de Convênio com a Secretaria do Meio Ambiente do Estado de São Paulo (SEMA); a compra de 10 coletores de 50 litros através de contribuição dos parceiros do projeto; pesquisa realizada no município para levantamento de 16 pontos estratégicos para distribuição dos coletores; investigação a campo para análise de quatro galpões visando conseguir um local para a realização da triagem dos resíduos; e utilização dos saquinhos de leite gerados na cidade para manuseio de mudas.

Outra conclusão importante a ser destacada nesta pesquisa é sobre as condições de trabalho dos trabalhadores com materiais recicláveis. Apesar dos trabalhadores catadores em Teodoro Sampaio possuírem uma jornada diária de trabalho maior que os trabalhadores da Usina de Triagem e Compostagem de Tarumã, seus rendimentos são inferiores. Em Tarumã 100\% dos trabalhadores realizam suas atividades com a separação dos resíduos na Usina de Triagem e Compostagem durante um período de 8 horas por dia. Já em Teodoro Sampaio, principalmente por conta da informalidade, há uma atuação menos organizada, chegando a $77 \%$, a quantidade de trabalhadores que realizam suas atividades na catação por um período entre 8 e 12 horas.

Porém, conforme pesquisa realizada em Tarumã, a maioria dos trabalhadores entrevistados, ou seja, 53\% afirmaram ter um rendimento mensal na faixa entre 2 e 3 salários mínimos. Já em Teodoro Sampaio $26 \%$ dos catadores obtiveram um rendimento de até 1 salário mínimo por mês e $74 \%$ conseguiram com suas atividades na catação obter uma renda na faixa entre 1 e 2 salários mínimos. 
Deve-se destacar que uma das principais dificuldades apresentadas pelos trabalhadores na hora de se inserir ou reinserir no mercado de trabalho formal refere-se à falta de especialização e/ou atualização profissional. Ao analisarmos a TAB. 9, podemos identificar que a maior parte dos trabalhadores têm até quatro anos de estudo, compondo $47 \%$ dos trabalhadores em Tarumã e 38\% dos trabalhadores catadores em Teodoro Sampaio.

Para finalizar esta pesquisa, ressalta-se que diversos estudos relacionados ao gerenciamento de resíduos sólidos vêm sendo realizados em vários municípios da UGRHI 22-Pontal do Paranapanema pelo Grupo de Pesquisa Gestão Ambiental e Dinâmica Sócioespacial (GADIS), vinculado à Faculdade de Ciências e Tecnologia/UNESP, campus de Presidente Prudente, em parceria com várias instituições públicas e privadas.

Essas pesquisas visam auxiliar o poder público municipal na tomada de decisões relativas ao gerenciamento dos seus resíduos visando uma gestão ambiental, econômica e socialmente adequada à realidade dos municípios no Pontal do Paranapanema. Dentre as ações já realizadas destaca-se o Diagnóstico dos Resíduos Sólidos em Teodoro Sampaio, elaborado por Fagundes, (2005), que em poder da Secretaria Municipal de Meio Ambiente, vem sendo utilizado para apoiar as tomadas de decisão quanto à implantação da coleta seletiva na cidade.

Diante dessas informações concluímos que a Educação Ambiental constitui importante ferramenta para o sucesso da coleta seletiva no município. Devendo haver, para tanto, destinação de mais recursos à capacitação de pessoal para atuar periodicamente em campanhas educativas e divulgação do programa de coleta seletiva.

\section{REFERÊNCIAS}

COMPANHIA DE TECNOLOGIADE SANEAMENTO AMBIENTAL - CETESB. Inventário estadual de disposição de resíduos sólidos. São Paulo: CETESB, 2006. Disponível em: $<$ http://www.cetesb.com.br/ $>$.
Acesso em 17 set. 2007.

DADOS DEMOGRÁFICOS dos municípios brasileiros. INSTITUTO BRASILEIRO DE GEOGRAFIA E ESTATÍSTICA on-line. 2007. Apresenta informações censitárias dos municípios brasileiros. Disponível em: $<$ http://www.ibge.com.br/>. Acesso em: 17 set. 2007.

FAGUNDES, D. C. Diagnóstico dos Resíduos Sólidos em Teodoro Sampaio - SP. 2005. 86 f. Trabalho de Conclusão de Curso. (Graduação em Geografia) Faculdade de Ciências e Tecnologia da Universidade Estadual Paulista. Presidente Prudente, 2005.

FELIPETTO, A. V. M. Conceito, planejamento. Rio de Janeiro: IBAM, 2007.

GONÇALVES, M. A. O movimento nacional dos catadores de resíduos recicláveis no Brasil. In: LEAL, A. C. et al. Educação ambiental e gerenciamento integrado dos resíduos sólidos em Presidente Prudente - SP: desenvolvimento de metodologias para a coleta seletiva, beneficiamento do lixo e organização do trabalho. Presidente Prudente-SP: UNESP/FAPESP. Relatório Final III Fase, 2005. 186 p.

IBGE - CIDADES. População estimada. 2006. Disponível em: $<$ http://www.ibge.gov.br/icadesat/ default.php>. Acesso em: 28 de ago. de 2007.

IBGE. Pesquisa Nacional de Saneamento Básico 2002. Instituto Brasileiro de Geografia e Estatística. Ministério do Planejamento, Orçamento e Gestão. Brasil. Disponível em: cd-rom. Acesso em: 15 fev. 2008.

ÍNDICE DE QUALIDADE DE ATERRO DE RESÍDUOS. Companhia de tecnologia de saneamento ambiental. CETESB on-line. 2006. Apresenta informações referentes ao IQR dos municípios do Estado de São Paulo. Disponível em: < http://www.cetesb. sp.gov.br/> Acesso em: 24 abr. 2007.

INSTITUTO DE PESQUISAS TECNOLÓGICAS IPT; COMPROMISSO EMPRESARIAL PARA RECICLAGEM - CEMPRE. Lixo municipal - manual de gerenciamento integrado. São Paulo: IPT/ 
CEMPRE, 1996.

JARDIM, N. S. Lixo municipal: manual de gerenciamento integrado. São Paulo: Instituto de Pesquisas Tecnológicas, 1995.

JUNKES, M. B. Procedimentos para aproveitamento de resíduos sólidos urbanos em municípios de pequeno porte. 2002. Dissertação (Mestrado) - Programa de Pós-graduação em Engenharia de Produção - Universidade Federal de Santa Catarina. Santa Catariana, 2002.

LOGAREZZI, A. Educação ambiental em resíduo: uma proposta de terminologia. In: Consumo e Resíduo: fundamentos para o trabalho educativo. São Carlos: EdUFSCar, 2006. 216 p.

Contribuições conceituais para o gerenciamento de resíduos sólidos e ações de educação ambiental. In: Resíduos Sólidos no Pontal do Paranapanema. Presidente Prudente: Antonio Thomaz Junior, 2004. $276 \mathrm{p}$.

LOPES, A. A. Estudo da Gestão e do Gerenciamento Integrado dos Resíduos Sólidos Urbanos no Município de São Carlos (SP). 2003. 176 p. Dissertação (Mestrado) - Escola de Engenharia de São Carlos, Universidade de São Paulo, São Carlos, 2003.

MESQUITA JR, J. M. Gestão integrada de resíduos sólidos. Rio de Janeiro: IBAM, 2007.

MINISTÉRIO DAS CIDADES. Lixo e CidadaniaGuia de ações e programas para a gestão de resíduos

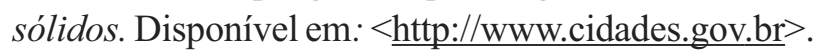
Acesso em: 11 de dez. de 2006.

SAVI, J. Gerenciamento integrado de resíduos sólidos urbanos em Adamantina-SP: análise da viabilidade da usina de triagem de RSU com coleta seletiva. 2005. 236 f. Tese (Doutorado) - Faculdade de Ciências e Tecnologia, Universidade Estadual Paulista. Presidente Prudente, 2005.

ZANIN M.; SILVA L.; CORREIA T. S. Identificação das condições de comercialização na cadeia da reciclagem de resíduos como subsídio para gestão de cooperativas. Unicamp, 2006. Disponível em: $<$ http:// www.cori.unicamp.br>. Acesso em: 02 jul. 2008. 